\title{
THE APPLICATION OF 3D LASER SCANNING IN THE SURVEY AND MEASURING OF GUYUE BRIDGE OF SONG DYNASTY IN YIWU CITY
}

\author{
Ning LU ${ }^{\mathrm{a}}$, Qi WANG ${ }^{\mathrm{b}}$, Shuai WANG ${ }^{\mathrm{c}}$, Rong ZHANG ${ }^{\mathrm{d}}$ \\ ${ }^{a}$ Doctor of Technical Science,Cultural Heritage Conservation Centre, Architecture Design \& Research Institute of Tsinghua \\ University, No.8 Zhongguancun East Road, Beijing, China - lvning_h@163.com \\ ${ }^{\mathrm{b}}$ Cultural Heritage Conservation Centre, Architecture Design \& Research Institute of Tsinghua University, No.8 Zhongguancun East \\ Road, Beijing, China - wangqi@ chcc.org.cn \\ ${ }^{\mathrm{c}}$ Cultural Heritage Conservation Centre, Architecture Design \& Research Institute of Tsinghua University, No.8 Zhongguancun East \\ Road, Beijing, China - 775286753@qq.com \\ ${ }^{\mathrm{d}}$ Cultural Heritage Conservation Centre, Architecture Design \& Research Institute of Tsinghua University, No.8 Zhongguancun East \\ Road, Beijing, China -zhangrong@chcc.org.cn
}

KEY WORDS: 3D laser scanning, Folding-arch, Original State Calculated, Measurement, Proportion, Analysis

\begin{abstract}
:
It is believed that folding-arch is the transitional form from beam to curved arch. Guyue Bridge, built in JiaDing 6year (A.D 1213) of Southern Song Dynasty, located in Yiwu City, Zhejiang Province in China, is one of typical objective examples for this transition. It possesses high historical, scientific, artistic, cultural and social values. Facing severe environmental problems and deteriorated heritage situation, our conservation team selected 3D laser scanning as basic recording method, then acquired the precise threedimensional model. Measured the fundamental dimension and components' sizes, we analysed its stable state. Moreover, combined with historic documents, we reasonably speculated and calculated the original sizes and important scales at the building time. These findings have significant research values as well as evidential meanings for future conservation.
\end{abstract}

\section{THE DEVELOPMENT OF CHINESE BRIDGES IN SONG DYNASTY}

According to the records, early in the spring and autumn period in China, bridges as one of forms of transportation have been appeared. "Using wood cross river is bridge now. "(Zhen.X, 121) Since thousands of year past, as the highly developed in economic cultural, technique in Song Dynasty, construction skills, bridges types and quantity has been working up to a climax. While inheriting the traditional types of former generations, including arch bridges, beam bridges, Song Dynasty made lots of innovations like rope-bridge and rainbow-shaped bridges. These nearly cover all bridge types in Chinese history.

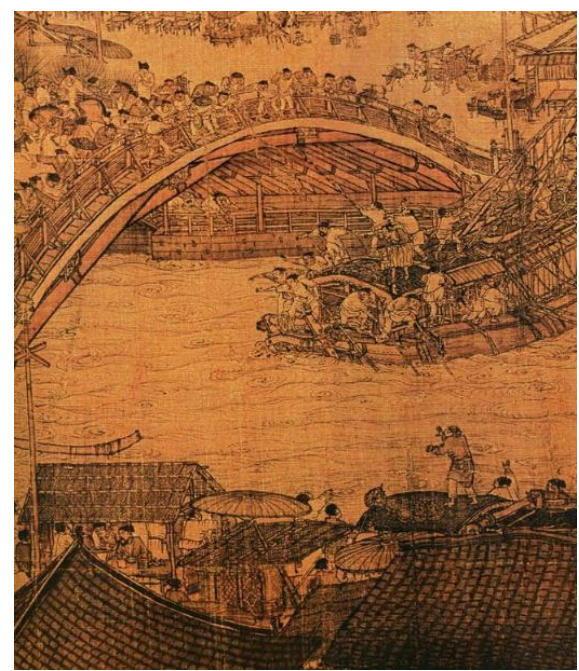

Figure 1. Rainbow-shaped Bridge draw in Riverside Scene at Qingming Festival in Song Dynasty
Meanwhile, great progress had been made in construction skill and technique at that time, including raft-shaped foundation created in Luoyang Bridge, huge-scale bridge built in Fujian Province, high-foot ship using fit for different archway of bridges in Fujiao bridge in Tanzhou and so on. During 300 years in Song Dynasty, especially in the last 100 years during Southern Song Dynasty, people built quantities of bridges. Only in the capital city Lin'an, hundreds of bridges ${ }^{(1)}$ were built. Moreover, considering regional distribution, Zhejiang provincial area had the largest number as follows.

\begin{tabular}{|l|l|l|l|l|}
\hline \multirow{2}{*}{ Region } & \multicolumn{2}{|l|}{ Number of Bridges Construction } & \multirow{2}{*}{ Total } \\
\cline { 2 - 4 } & $\begin{array}{l}\text { New } \\
\text { construction }\end{array}$ & Restoration & Repair & \\
\hline Jiangsu & 21 & 51 & 3 & 75 \\
\hline $\begin{array}{l}\text { Zhejian } \\
\text { g }\end{array}$ & 21 & 58 & 4 & 83 \\
\hline Fujian & 1 & 0 & 0 & 1 \\
\hline
\end{tabular}

Table 1. The Construction Situations of Bridges in Southern Part in Southern Song Dynasty (Chuanxian.M, 2007)

Based on the diagram, there are 76 bridges built in Song and Yuan period in Zhejiang Province exist now, including 29 arch bridges, 47 beam bridges and one pontoon bridge. Among the 29 arch bridges, 25 bridges are common curbed-arch ones while only 4 are folding-arch bridges, including Lingxi Bridge in Yongkang City, Monk Bridge in Sangzhou City, West

(1) According to the records in Qiandao Linan Zhi, Xianfu Linan Zhi, there were 73 bridges in Linan city in Qiandao period (1165-1173), while until Xianchun period (12651274), the number increased to 559. Considering duplicate records, almost 300 bridges were new built. 
Mountain Bridge in Jiande City and Guyue Bridge in Yiwu City. Actually, folding-arch bridges are one of special and important forms in Chinese bridge development history and, with striking local features, only exist in Zhejiang areas at present.

From many scholars' point of view, folding-arch is the transition form from beam to circular arch, which has been proved in archaeological discovery of tombs in Han Dynasty. The evolution from corbel to three, five or seven folding-arch, then to curved arch finally, is surprisingly similar to the west world, which also from pyramid blind arch to folding-arch, then became curved arch. Thus, the evolution procedure is deemed to the law of development in Chinese ancient bridges history. Generally speaking, material characteristics of beam-bridge limit the span for a long period. Ancient workers, after lots of trials, invent corbel beam-bridge like a long arm. Then, three-folding-arch bridge were appeared. The folding arch number turned to five, seven as time went on. The bigger the folding arch number, the closer the real curved arch. "Fortunately, some transition form bridges, with early construction feature, are preserved in Zhejiang Province, which provide meaningful examples for research of this change." (Shuheng.Z, 1993) In this regard, the birth of Chinese curved arch bridges are closely related to the unique evolution of folding-arch bridges. Thus 4 bridges of Song Dynasty exist in Zhejiang Province now embrace high historic, scientific and artistic values as important research evidence.

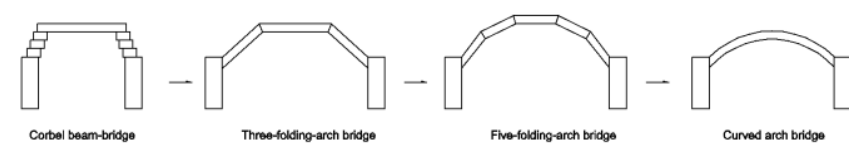

Figure 2. Developing Process From Beam to Arch

Above these 4 folding-arch bridges, Guyue Bridge in Yiwu City, with earliest and finest built time as well as most complicate construction $^{(2)}$, offers multiple relics', cultural and social values. Therefore, application and research on its current situation, through technique methods, is deemed to foundation of conservation, with significant meaning for repairing, explanation and interpretation in future.

\section{GUYUE BRIDGE INTRODUCTION AND PROJECT BACKGROUND}

The Guyue Bride, built in 1213 A.D., is located in the $25 \mathrm{~km}$ southeast of Yiwu City and 100 meters to the west of Chian Town. The Chinese characters, "Huang Song Jia Ding Kui You Ji Qiu Run Yue Jian Zao", caved on the stone beam on the south side could prove the year in which the bridge was built. It is said that the bridge was built under the supervision of Xu Qiao (Lord Wenqing), the Minister of Engineering Department of the Nansong Dynasty. The bridge was discovered during the historical relic survey in 1982, and was added to the National Heritage List by the State Council in 2001.

The Guyue Bridge spans over the Dragon Stream at its turn. The Dragon Stream has small flow all over the year and may have two or three floods each year, which may lead to the overflow of the stream, but the water will recede fast after the floods.

${ }^{(2)}$ Lingxi Beidge, Monk Bridge are three-folding-arch bridges, while West Mountain Bridge and Guyue Bridge are fivefolding-arch.

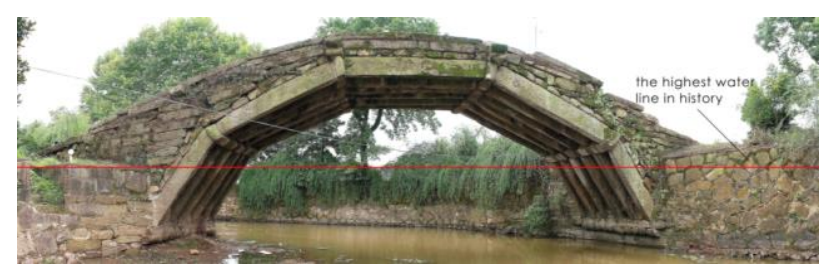

Figure 3. the Highest Water Line in History

The Guyue Bridge is a folding-arch bridge built with volcanic breccia through the single-arch, vertical connection and adjoin piling method. And the body of the bridge is divided into four floors. The bridge has simple and unsophisticated appearances and unique structure with great historical, artist, scientific and cultural values. With the history of more than 1,000 years, the bridge body has been badly damaged, and the major load bearing structure has been displaced. In order to check the statues of the bridge and analyze the major risks and causes, judge the stability of the structure as well as make the restoration plan according to its conditions, the working team from Cultural Heritage Conservation Centre of the Tsinghua University, under the authorization of the local relic authority of Yiwu, has started comprehensive investigation and research over the Guyue Bridge since August, 2014, so as to inherit the values of the bridge to our future generations actually and completely.

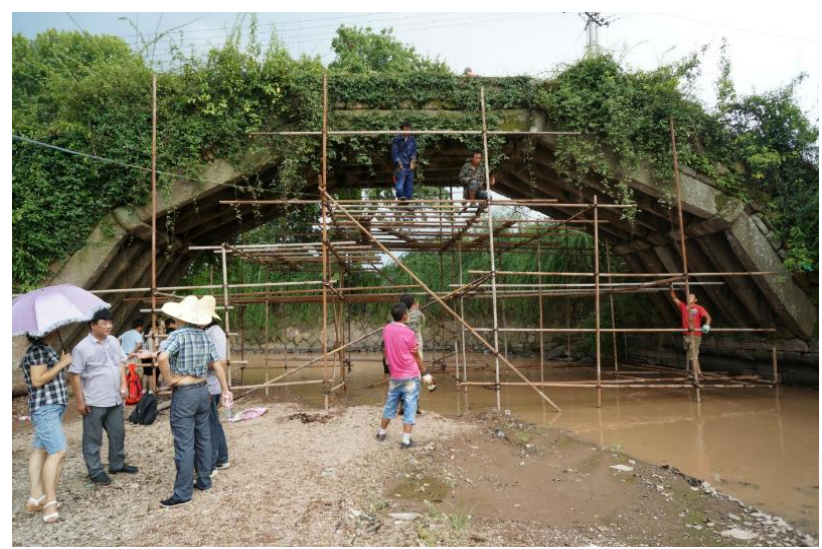

Figure 4. Guyue Bridge and its Environment

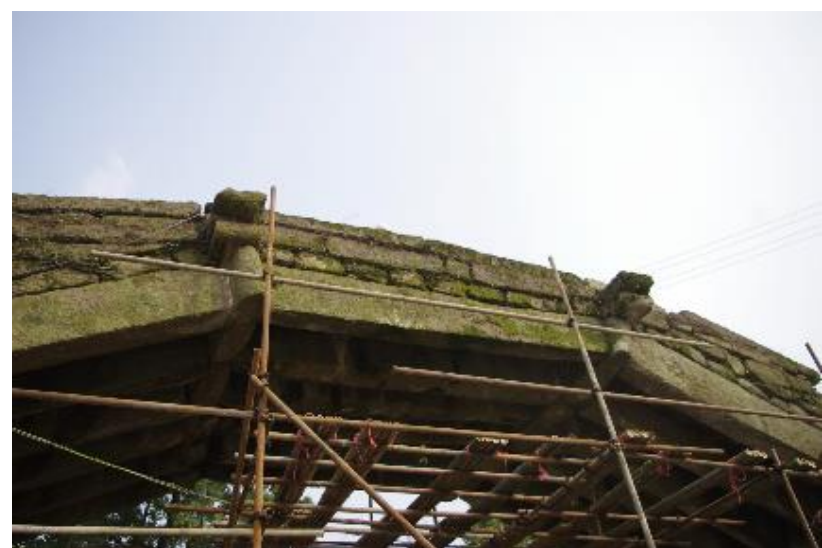

Figure 5. Historic Records Caved in the West Side

In order to learn the structure of the Guyue Bridge more clearly and directly, as well as analyze its structure accurately, the team has conducted the research in many aspects based on the 3D laser scanning method during this investigation. 


\section{APPLICATION AND ANALYSIS OF 3D LASER SCANNING IN THE CASE}

\subsection{D Laser Scanning}

The 3D laser scanning is used to record the physical dimensions of the bridge. We used the 3D laser scanner to conduct noncontact precise scanning over the bridge. According to the on-site investigation, the surface data of the bridge can be obtained from the 3D surface model of the bridge so as to record the 3D information and current conditions of the bridge body. The equipment we used is the FARO Focus3D X 330 3D laser scanning equipment.

The equipment can obtain 3D space points at the rate of 122,000 points to 976,000 points per second. The minimum interval between any two points can be as small as $1 \mathrm{~mm}$, and the error of single point measurement is less than $2 \mathrm{~mm}$, which could meet the requirements in terms of measurement precision and resolution. The two-axle supplementary accuracy of the equipment is $0.015^{\circ}$, which can be used to control the horizontal and vertical directions of the coordinate system. Even though with the weathering effects, the stone strips in the bottom of the bridge, the missing of the locking stones and cracks could also be expressed with Focus $3 \mathrm{D}$ X 330 .

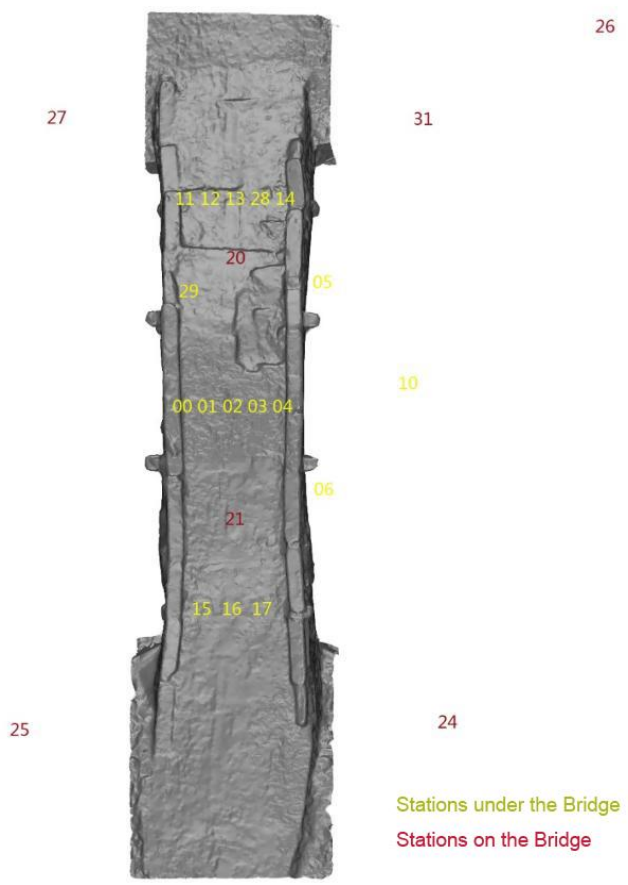

Figure 6. Scanning Stations Around the Bridge

There are 26 stations used for the scanning work in total, including 7 stations above the bridge and 19 under the bride. Within the effective range, the average point-distance is $2 \mathrm{~mm}$, and the data volume is $2 \mathrm{G}$. The outdoor working time was 2 days. And we spent three days to collect the complete point-cloud data, eliminate noise, optimize the points, build the model and generate the accurate 3D model of the Guyue Bridge

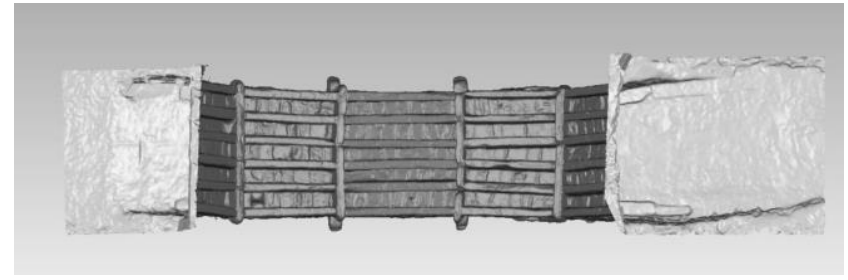

Figure 7. model of Guyue Bridge

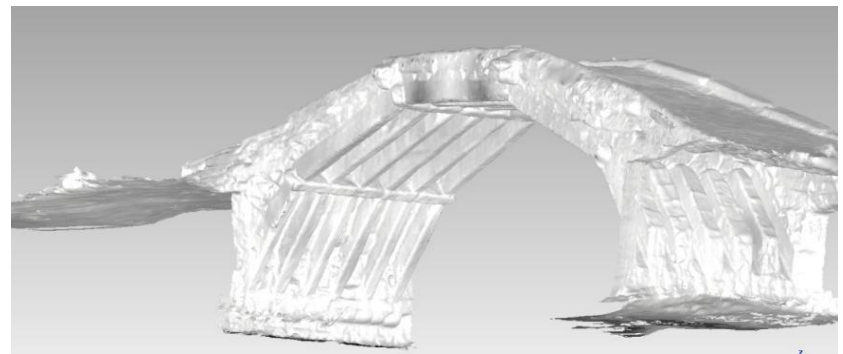

Figure 8. Model Perspective

\subsection{The Structure and Measure of the Model}

According to the scan results it can be seen that the Guyue Bridge has 6 folding-arches stand side by side, which are connected together by stone cross beams. The structure could be divided into four layers.

As the main weight-bearing structure of the bridge, the bottom layer is composed of six pentagonal folding-arches, joining with 4 groups stone cross beams. Each folding-arch is made up with five girt strips. The stone cross beam was chiselled out of the groove, so that the component of the arch and the stone cross beam could be connected closely. Meanwhile, in order to make sure the integrity and flexibility of the bridge as well, each group of the stone cross beam, which stabilize the 6 foldingarches, was two parts instead of one. Moreover, the two parts are not aligned in the line; instead they are arranged alternate permutation in a creative way.

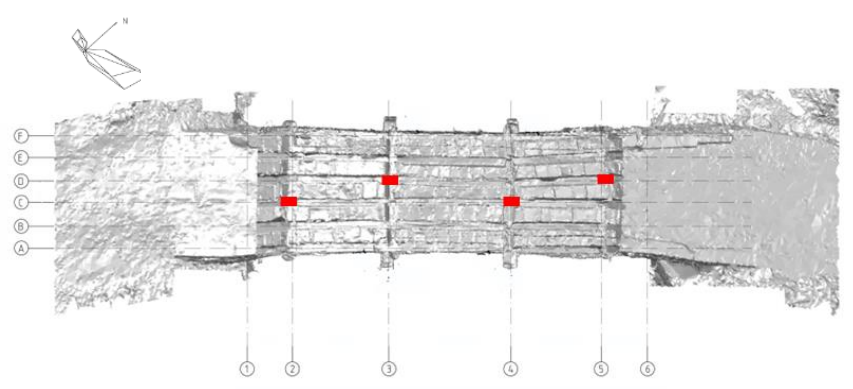

Figure 9. Structure of Guyue Bridge (red line: connection between the two stone cross beam)

The second layer of the bridge is the slate above the weighbeating layer. This layer is composed of slate tiled with the vertical direction. Looking up from the bottom of the bridge, it can be seen, among the interspace of the girt strips, it is different in size and number of all the slabstones. According to statistics, there are 148 pieces of slate in all. Mortars are used for joining all the slabstones, with local cinerite as the main components.

The third layer is packed bed, which is filled up with different sizes of the gravel and loess, using boulder strips stand by sides at the same time. The fourth layer above is the bridge floor. The 
corresponding position of the stone cross beams are vertically paved by boulder strips. At the centre of the deck, there are slates paved along the bridge direction. Then the rest parts of the bridge are paved by boulder strips strewn at random along the bridge direction. At present, the pavement is damaged partly which were repaired with pebbles and sand in the late repairing. Also, there are rectangular stone slabs above the deck layer along the bridge on both sides.

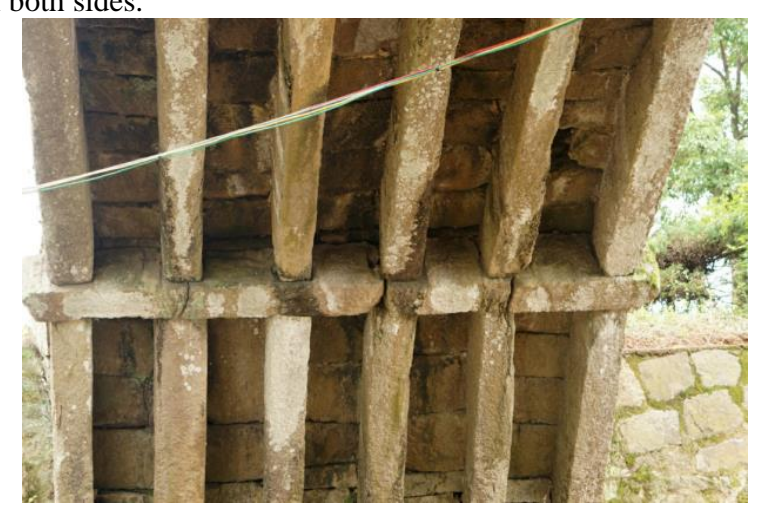

Figure 10. Underside of the Bridge

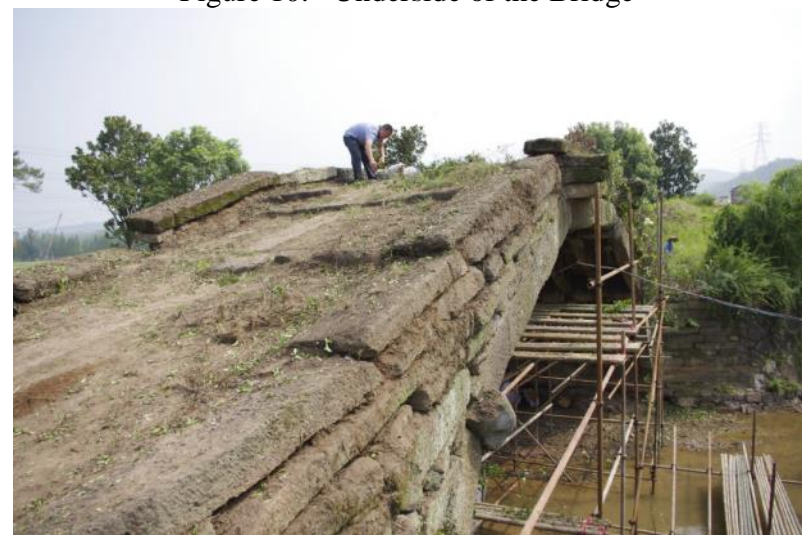

Figure 11. Situation of Bridge Floor

With the accurate measurement of 3D model, we can obtain the basic dimensions of the Guyue Bridge: the bridge is 31.20 meters in length, with 14.67 meters long of the arch. The height of the arch is 4.99 meters, and the width of the bridge is 4.91 meters on both sides while 4.45 meters in middle.

The length of the east and west approach-bridges are 7.65 meters, with about $25^{\circ}$ of the slope. The height of the arch is 3.745 meters. In addition, the sizes of each weight-bearing component can also be obtained by 3D model measuring.

\begin{tabular}{|c|c|c|c|c|c|c|}
\hline & $\begin{array}{l}\text { Axis } \mathrm{A} \\
(\mathrm{cm})\end{array}$ & $\begin{array}{l}\text { Axis B } \\
(\mathrm{cm})\end{array}$ & $\begin{array}{l}\text { Axis C } \\
(\mathrm{cm})\end{array}$ & $\begin{array}{l}\text { Axis D } \\
(\mathrm{cm})\end{array}$ & $\begin{array}{l}\text { Axis } \\
\mathrm{E}(\mathrm{cm})\end{array}$ & $\begin{array}{l}\text { Axis F } \\
(\mathrm{cm})\end{array}$ \\
\hline $\begin{array}{l}\text { Beams } \\
\text { between } \\
\text { Axis 1-2 }\end{array}$ & $\begin{array}{l}32 \times 52 \\
\times 278\end{array}$ & $\begin{array}{l}30 \times 45 \\
\times 285\end{array}$ & $\begin{array}{l}35 \times 56 \\
\times 288\end{array}$ & $\begin{array}{l}32 \times 48 \\
\times 282\end{array}$ & $\begin{array}{l}39 \times \\
50 \times \\
278\end{array}$ & $\begin{array}{ll}29 \times \\
49 & \times \\
281 & \end{array}$ \\
\hline $\begin{array}{l}\text { Beams } \\
\text { between } \\
\text { Axis 2-3 }\end{array}$ & $\begin{array}{l}31 \times 49 \\
\times 362\end{array}$ & $\begin{array}{l}27 \times 56 \\
\times 355\end{array}$ & $\begin{array}{l}30 \times 51 \\
\times 365\end{array}$ & $\begin{array}{l}27 \times 53 \\
\times 351\end{array}$ & $\begin{array}{l}30 \times \\
50 \times \\
350 \\
\end{array}$ & $\begin{array}{l}32 \times \\
47 \times \\
354\end{array}$ \\
\hline $\begin{array}{l}\text { Beams } \\
\text { between } \\
\text { Axis 3-4 }\end{array}$ & $\begin{array}{l}29 \times 49 \\
\times 378\end{array}$ & $\begin{array}{l}34 \times 53 \\
\times 380\end{array}$ & $\begin{array}{l}33 \times 52 \\
\times 382\end{array}$ & $\begin{array}{l}28 \times 55 \\
\times 375\end{array}$ & $\begin{array}{l}31 \times \\
50 \times \\
385\end{array}$ & $\begin{array}{l}30 \times \\
51 \times \\
380\end{array}$ \\
\hline $\begin{array}{l}\text { Beams } \\
\text { between } \\
\text { Axis 4-5 }\end{array}$ & $\begin{array}{l}30 \times 45 \\
\times 377\end{array}$ & $\begin{array}{l}30 \times 52 \\
\times 380\end{array}$ & $\begin{array}{l}29 \times 49 \\
\times 381\end{array}$ & $\begin{array}{l}33 \times 48 \\
\times 385\end{array}$ & $\begin{array}{l}29 \times \\
53 \\
381\end{array}$ & $\begin{array}{ll}26 \times \\
50 & \times \\
375 & \\
\end{array}$ \\
\hline $\begin{array}{l}\text { Beams } \\
\text { between } \\
\text { Axis 5-6 }\end{array}$ & $\begin{array}{l}29 \times 54 \\
\times 309\end{array}$ & $\begin{array}{l}39 \times 5 \\
\times 309\end{array}$ & $\begin{array}{l}32 \times 48 \\
\times 335\end{array}$ & $\begin{array}{l}35 \times 48 \\
\times 318\end{array}$ & $\begin{array}{l}30 \times \\
50 \times \\
278\end{array}$ & $\begin{array}{l}32 \times \\
55 \times \\
315\end{array}$ \\
\hline
\end{tabular}

Table 2. Table of Components' Sizes

\subsection{Analysis Based on Precise Measurement}

According to the analysis of the data above, we found the construction module in Song dynasty of Guyue bridge. In ancient China, Chi and Cun (units of measurement in ancient China, 1chi=10cun) were used as the basic units to design and construct. By calculating, the basic unit is: 1 Construction Ruler $(1 \mathrm{chi})=31.2 \mathrm{~cm}$, exactly right the same as Construction Ruler in Song dynasty $(1 \mathrm{chi}=31.186 \mathrm{~cm})$. Through the calculation we can see, that the length of the bridge is just $100 \mathrm{chi}$, the length of the approach bridge and the bridge itself are both 50 chi. Span of the axis is $48 \mathrm{chi}$, while the height of the arch from bottom to top is $12 \mathrm{chi}$. It is just a triangle with elegant proportion: the ratio of the bottom edge's length and height of the arch is 4:1(the following figure). Therefore, considering the features of building skills at that period, we recognized that the triangle were rightly consistent with the setting-out at the beginning of the bridge's construction.

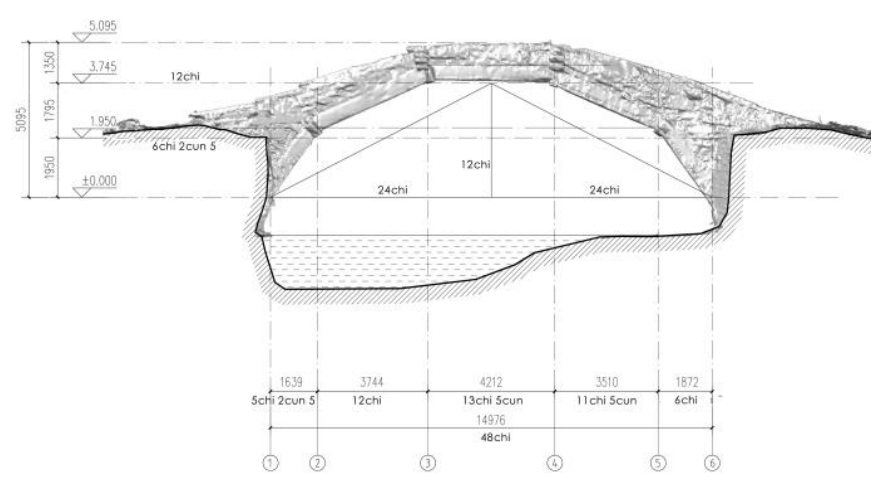

Figure 12. Important Structure Proportion of the Bridge

Moreover, according to the scanning result, the original contraction of the bridge (looks like the section of concave lens) can be seen obviously, though six folding-arches all have deviated in certain extent since the force of river or earthquake during thousands of years. The contraction follows the rules, such as the distance of two axis of the widest position on two sides is $860 \mathrm{~mm}$, converting Song construction ruler $2.75 \mathrm{chi}$; while the narrowest position is only $780 \mathrm{~mm}$, converting $2.5 \mathrm{chi}$. The total axis distance contracts from $13.75 \mathrm{chi}$ to $12.5 \mathrm{chi}$. It suggests Guyue Bridge have inward prestressing force at the beginning of construction. Through the exquisite design of the bridge, we could learn the excellent technology of bridge building.

\begin{tabular}{|l|l|l|l|l|}
\hline & $\begin{array}{l}\text { measurement } \\
(\mathrm{mm})\end{array}$ & $\begin{array}{l}\text { measurement } \\
(\mathrm{chi})\end{array}$ & $\begin{array}{c}\text { calculated } \\
(\mathrm{chi})\end{array}$ & $\begin{array}{c}\text { calculated } \\
(\mathrm{mm})\end{array}$ \\
\hline Length & 31202 & 100 & 100 & 31200 \\
\hline $\begin{array}{l}\text { Side } \\
\text { width }\end{array}$ & 4836 & 15.5 & 15.5 & 4836 \\
\hline $\begin{array}{l}\text { Middle } \\
\text { width }\end{array}$ & 4445 & 14.25 & 14.25 & 4446 \\
\hline $\begin{array}{l}\text { Side } \\
\text { axis } \\
\text { width }\end{array}$ & 860 & 2.75 & 2.75 & 860 \\
\hline $\begin{array}{l}\text { Middle } \\
\text { axis } \\
\text { width }\end{array}$ & 788 & 2.52 & 2.5 & 780 \\
\hline $\begin{array}{l}\text { Total } \\
\text { Axis } \\
\text { width }\end{array}$ & 4299 & 13.77 & 13.75 & 4290 \\
\hline
\end{tabular}

Table 3. Components' Sizes of Guyue Bridge Calculated 


\begin{tabular}{|l|l|l|l|l|}
\hline & $\begin{array}{l}\text { measurement } \\
(\mathrm{mm})\end{array}$ & $\begin{array}{l}\text { measurement } \\
(\mathrm{chi})\end{array}$ & $\begin{array}{l}\text { calculated } \\
(\mathrm{chi})\end{array}$ & $\begin{array}{c}\text { calculated } \\
(\mathrm{mm})\end{array}$ \\
\hline Span & 14976 & 48 & 48 & 14976 \\
\hline $\begin{array}{l}\text { Arch } \\
\text { height }\end{array}$ & 3745 & 12 & 12 & 3744 \\
\hline
\end{tabular}

Continued Table 3. Components' Sizes of Guyue Bridge Calculated

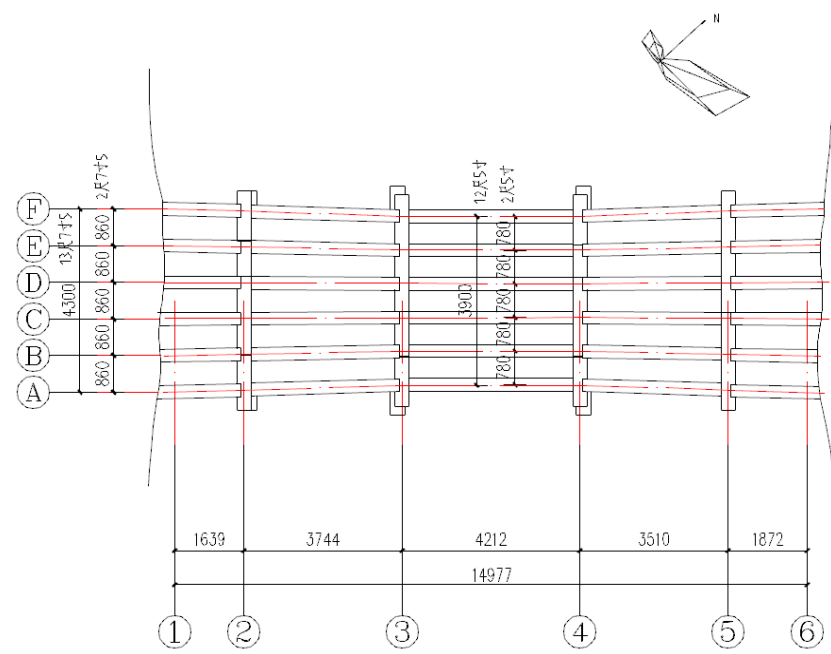

Figure 13. Original State Calculated of Guyue Bridge Contraction and Axis

On the other hand, model of 3D scanning becomes important proof for judgment of the current stability of heritage. It can be seen that six folding-arches all have deviated in certain extent, according to the analysis of the model. The two columns closed to the downstream are in the most serious situation. Deviation direction is just corresponding to the broken point of stonecross beams on the bottom of bridge, which explained further that the broken of stonecross beams provided bad impact for the integrity of the bridge.

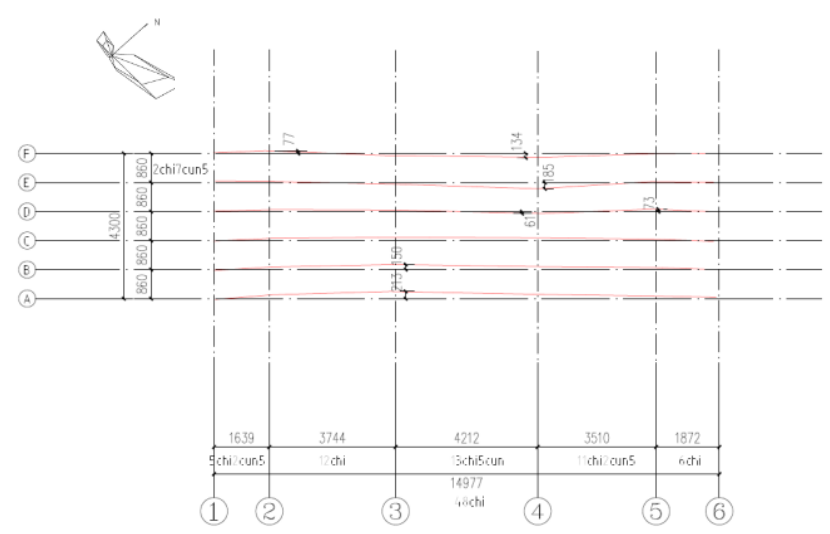

Figure 14. the Drawing of Axis Deviation

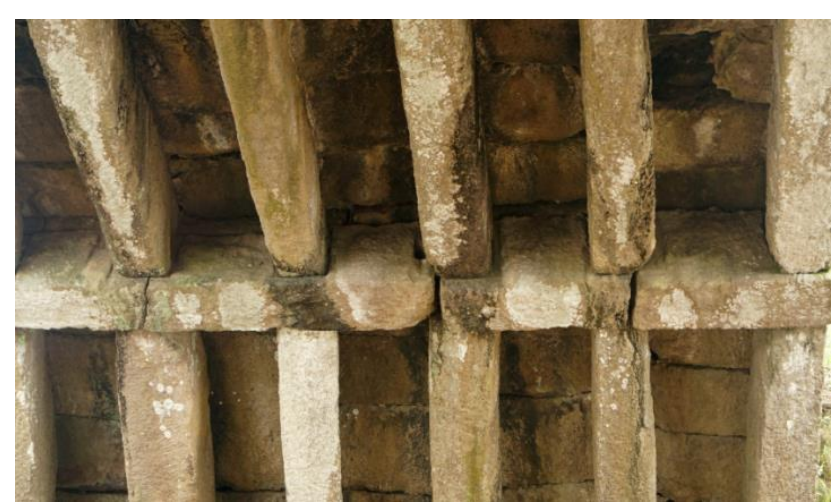

Figure 15 the Rupture of the Stone Cross Beam

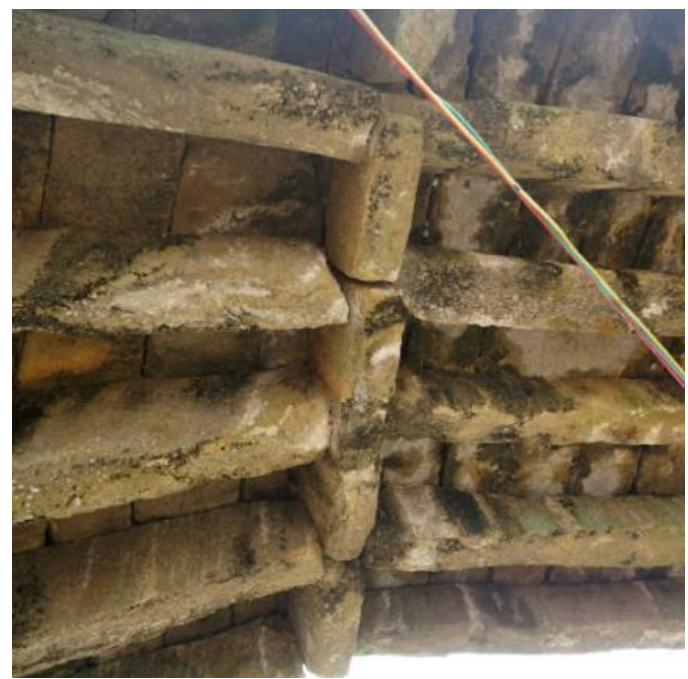

Figure 16. Current State of Stone Cross Beam

In conclusion, data and structure analysis based on 3D scanning model above provide evidence for future repair. We can put back the stone components in the folding-arch to right position in suitable conditions, ensuring authenticity and integrity in heritage sustainable development.

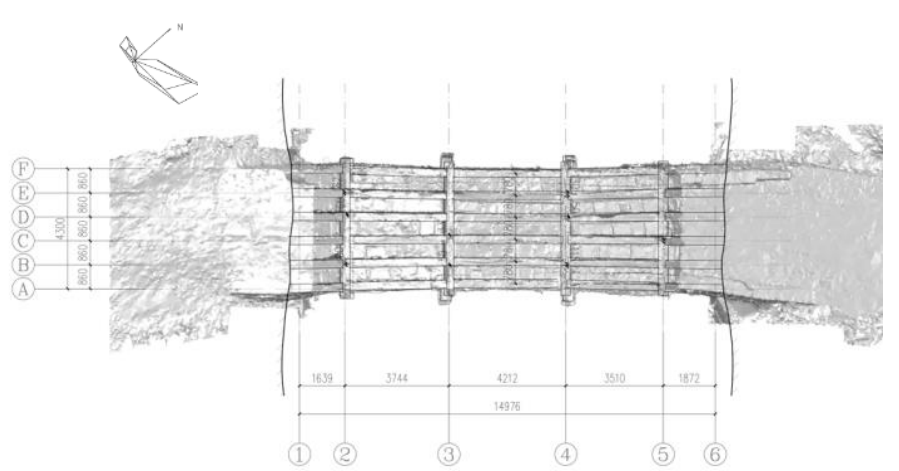

Figure 17. The Drawing of Homing the Beams (Model is based on survey now, line graph is the beams in right place after homing)

\section{CONCLUSION}

In the application and research of Guyue Bridge, 3D laser scanning method is used as base of measure, application on current situation and historic resources are also taken into account by our Tsinghua conservation team as follows: 
Firstly, the most accurate data model was obtained through 3D laser scanning, then measuring data including both main dimension and basic components sizes could be clearly seen. Considering records in historic documents, we calculated, after compared with research findings on Chi in Song dynasty, reasonable historical building way and skill features of the bridge. As a result, length, height and width of the bridge were all precisely measured and calculated at the beginning of construction; also they three had clear scaling relation. Moreover, the bridge was beautifully shaped, with ingenious design. It is undoubtedly the best case in Zhejiang area.

Furthermore, the analysis of the model is also useful testimony on its stabilization judgment. Compared current structure sizes to beginning sizes, we can acquire specific data on its deformation and deviation. Combined with chemical research on building materials as well as physical structure analysis, the findings can be deemed as basic foundation when repairing or restoration in future.

Through the application in the case, we found 3D laser scanning method, as one of modern high-tech measuring way, is not only valuable in heritage information obtaining and recording, more important to some degree, is can be one of basic instrument in heritage application and research helping us understanding original appearance of cultural heritage. Compared precisely current sizes and scales to the historic documents, we can speculate the original situation of heritage, and know deformation also. With monitor data, structure and material analysis, it is probably known both the deterioration and changing procedure, and stable state of cultural heritage as well. Finally, it can be essential proof in future conservation issues.

\section{REFERENCES}

Chuanxian Meng. Situations of Bridges in Southern Song Dynasty from Songyuan Fangzhi Congkan. Journal of Wuhan Jiaotong Polytechnic,.2007(9). pp.48-50

Shuheng Zhang.,1993. Research on Bridges in Song Dynasty in Zhejiang. Beijing, P.R. China,pp. 320-322.

Zhen Xu., 121. 1989 replicated. Shuowen Jiezi, Origin of Chinese Characters.Beijing, P.R. China,pp. 29. 